\title{
Cheat Protection in Online Games
}

\author{
Stijn Volckaert \\ stijn.volckaert@cs.kuleuven.be \\ imec-DistriNet, KU Leuven Ghent Technology Campus \\ Gent, Belgium
}

\begin{abstract}
Competitive online video gaming (or eSports for short) is a booming industry. Current estimates predict global revenues of well over 1 billion dollars by the end of this year [5], Twitch.tv the largest eSports streaming network is now one of the biggest sites on the internet [2], and the International Olympic Committee is even considering to include eSports in the 2024 Summer Olympics [6].

With this rising popularity comes a dark side in the form of cheating, however. Cheaters are willing to subvert the rules of the game by any means necessary. Many of them pay monthly subscription fees to get access to exclusive cheating software created by hackers [3].

In this talk, I will discuss the most prevalent types of cheats used in online games and show how they give players a competitive advantage. I will then highlight the various steps that go into creating a cheat and give an overview of the various techniques and tools hackers use in each step, ranging from debuggers, differential data analysis tools [1], API hooking [4], bytehacking, etc.

Next, I will present cheat mitigation strategies that can be incorporated into a game's design, and detection techniques that can be applied in both client-side and server-side cheat-protection software.

Finally, I will zoom in on some of the most popular client-side anti-cheat solutions and highlight some of their capabilities.
\end{abstract}

\section{CCS CONCEPTS}

- Security and privacy $\rightarrow$ Software reverse engineering; • Applied computing $\rightarrow$ Computer games.

\section{KEYWORDS}

Online Gaming, Cheating, Anti-Cheat, Anti-Tampering, Obfuscation

\section{ACM Reference Format:}

Stijn Volckaert. 2019. Cheat Protection in Online Games. In 3rd Software Protection Workshop (SPRO '19), November 15, 2019, London, UK. ACM, New York, NY, USA, 1 page. https://doi.org/10.1145/3338503.3357726

\section{BIOGRAPHY}

Stijn Volckaert is an Assistant Professor of Computer Science in the imec-DistriNet group at KU Leuven. He obtained his Ph.D. degree from Ghent University in 2015, where he was advised by Prof. Bjorn

Permission to make digital or hard copies of part or all of this work for personal or classroom use is granted without fee provided that copies are not made or distributed for profit or commercial advantage and that copies bear this notice and the full citation on the first page. Copyrights for third-party components of this work must be honored

For all other uses, contact the owner/author(s).

SPRO '19, November 15, 2019, London, United Kingdom

(c) 2019 Copyright held by the owner/author(s).

ACM ISBN 978-1-4503-6835-3/19/11.

https://doi.org/10.1145/3338503.3357726

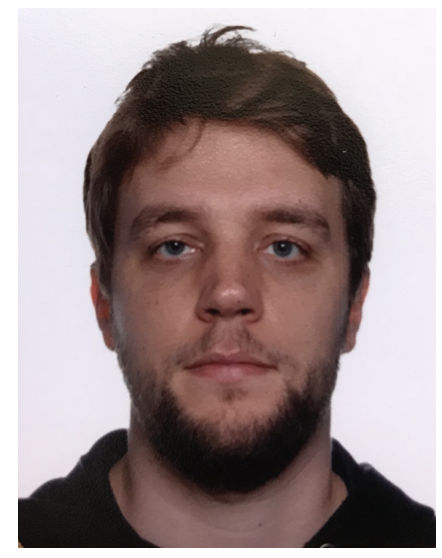

De Sutter and Prof. Koen De Bosschere. The Research Foundation Flanders awarded his dissertation with the IBM Innovation Award 2016.

Stijn then spent three years working as a post-doctoral scholar with Prof. Michael Franz at the Donald Bren School of Information and Computer Science at the University of California, Irvine.

Stijn's research interests include the use of software diversity for improved systems security, exploit mitigations, multi-variant execution, and security in online gaming.

In addition to his academic research, Stijn developed and maintains a popular cheat protection solution for Unreal Engine games. He is also a maintainer of the Unreal Tournament code base.

\section{REFERENCES}

[1] 2019. Cheat Engine. https://www.cheatengine.org

[2] Alexa. 2019. twitch.tv Competitive Analysis. https://www.alexa.com/siteinfo/ twitch.tv

[3] Stefano De Paoli and Aphra Kerr. 2010. "We Will Always Be One Step Ahead of Them" A Case Study on the Economy of Cheating in MMORPGs. Fournal of Virtual Worlds Research 2, 4 (2010).

[4] Galen Hunt and Doug Brubacher. 1999. Detours: Binary Interception of Win32 Functions. In 3rd USENIX Windows NT Symposium.

[5] Reuters. 2019. Global esports revenues to top $\$ 1$ billion in 2019: report. https://www.reuters.com/article/us-videogames-outlook/ global-esports-revenues-to-top-1-billion-in-2019-report-idUSKCN1Q11XY

[6] BBC Sport. 2018. Paris 2024 Olympics: Esports 'in talks' to be included as demonstration sport. https:/www.bbc.com/sport/olympics/43893891 